\title{
Multiple Juvenile Xanthogranuloma of the Eyelids
}

\author{
Hidetsugu Mori Yuta Nakamichi Kanji Takahashi \\ Department of Ophthalmology, Kansai Medical University, Osaka, Japan
}

\section{Established Facts}

- Eyelid lesion with juvenile xanthogranuloma (JXG) reveals a solitary lesion.

- JXG commonly occurs in infants.

\section{Novel Insights}

- We describe an unusual case of JXG with onset at 10 years of age that was located in both eyelids with multiple nodules in addition to systemic cutaneous nodules.

\section{Keywords}

Juvenile xanthogranuloma · Eyelid · Touton giant cells · Non-Langerhans cell histiocytosis

\begin{abstract}
Juvenile xanthogranuloma (JXG) is a rare and benign tumor in infants. A solitary lesion on the eyelid has been reported in patients with JXG. We report a 15-year-old boy with multiple involvement of JXG on both eyelids. A mass on the left inner canthus was resected because of disturbance of the visual field and a risk of malignancy in terms of central ulceration in the lesion. The mass was examined by light microscopy. The mass had Touton giant cells with a wreath of nuclei surrounded by foamy histiocytes. No malignancy was observed. The mass showed no recurrence after resection.

(c) 2017 The Author(s)

Published by S. Karger AG, Basel
\end{abstract}

\section{KARGER}

E-Mail karger@karger.com www.karger.com/oop

\section{The Author(s) \\ Published by S. Karger AG, Basel \\ Karger \\ open access}

This article is licensed under the Creative Commons AttributionNonCommercial-NoDerivatives 4.0 International License (CC BYNC-ND) (http://www.karger.com/Services/OpenAccessLicense). Usage and distribution for commercial purposes as well as any distribution of modified material requires written permission.

\section{Introduction}

Juvenile xanthogranuloma (JXG) is generally a rare and benign disorder that occurs in the skin of infants or in early childhood [1-4]. Most cutaneous granulomatous lesions are localized in the head, neck, trunk, and extremities and stabilize or regress by $1-5$ years spontaneously $[2,5,6]$. Cutaneous nodules and papules of JXG are yellowish-orange and are several millimeters in diameter [1, 2]. The diagnosis of JXG is based on clinical features of characteristic nodules or papules and a histopathological examination by incisional biopsy.

Extracutaneous JXGs in the central nervous system, lungs, heart, liver, testicles, bone marrow, and blood cells are rare [7-12]. Ocular involvement in patients with cutaneous JXG is the most common symptom in extracutaneous JXG [2, 13-15]. Ocular involvement of JXG in- 

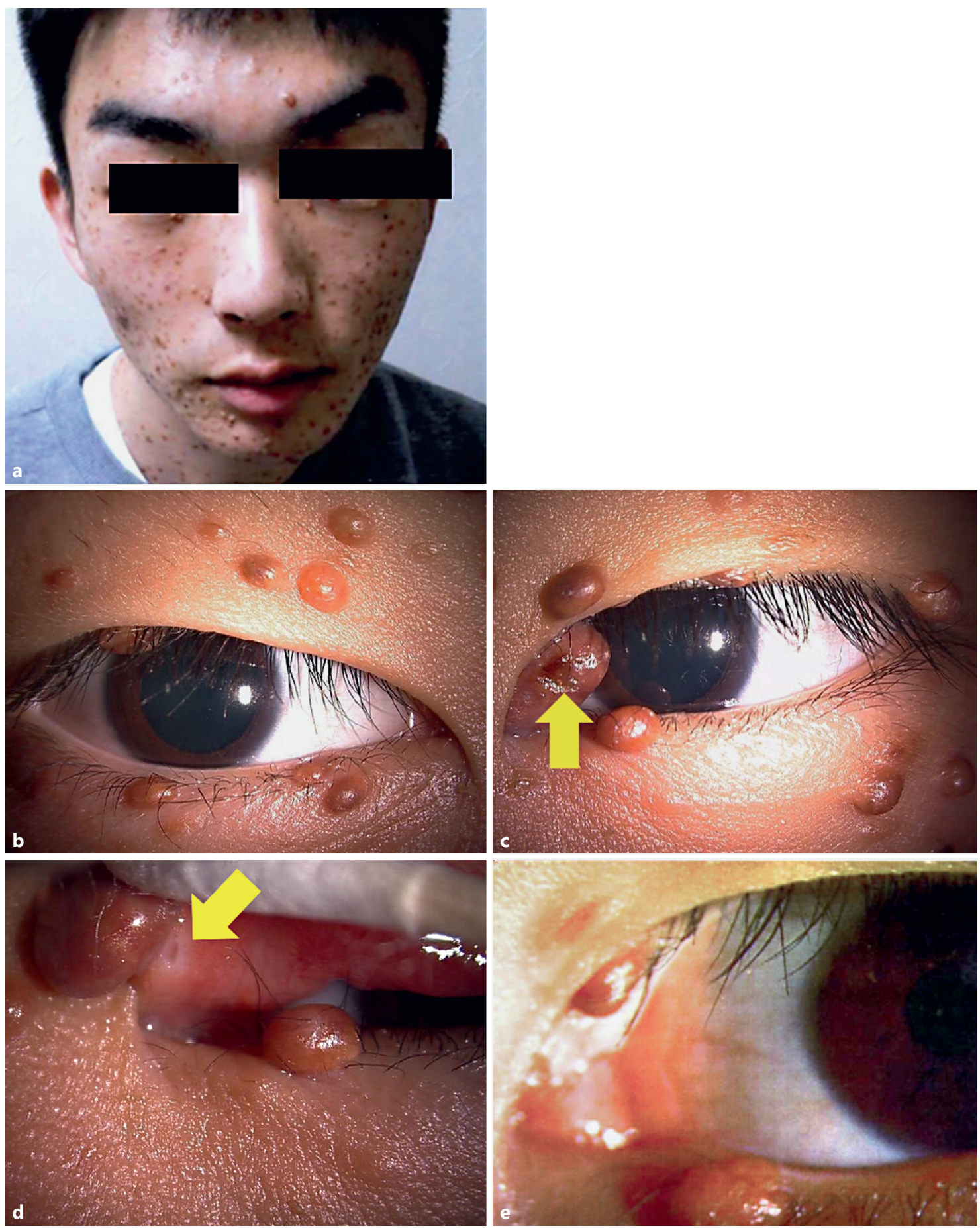

Fig. 1. Clinical findings. a Initial facial findings. Multiple nodules were observed over the face, including both eyelids. b Initial right eyelid findings. Multiple nodules were observed around eyelid as well as the left eye. c Initial left eyelid findings. A $5 \times 10$-mm diameter painless lesion on the inner canthus shows central ulceration (arrow). d Left lacrimal punctum findings (preoperation). The mass does not obstruct the left lacrimal punctum (arrow). e Postoperative findings ( 36 months postoperatively). The mass was resected completely and showed no recurrence. 

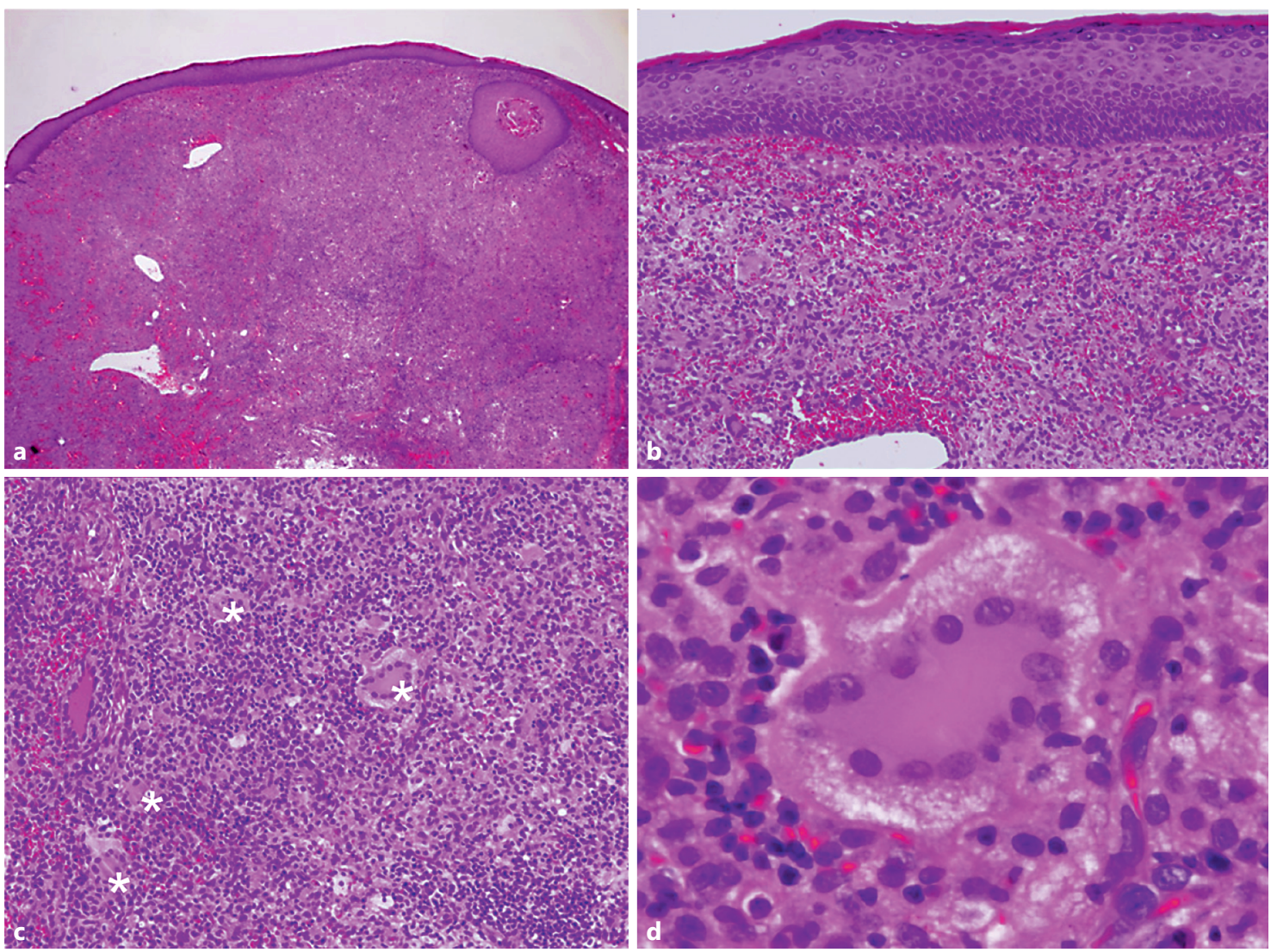

Fig. 2. Light microscopic findings of the mass. a Gross appearance of the lesion shows a partitioned structure and infiltration of small cells $(H \& E, \times 50)$. b An inflammatory lesion consists of epithelioid histiocytes, lymphocyte, and an eosinophilic cystoplasm with partial hemorrhage sparing between the subepithelial and dermic lay- er in addition to thickening in the epidermis (H\&E, $\times 100)$. c Multinucleated giant cells are present among histiocytes $\left(^{*}\right)(\mathrm{H} \& \mathrm{E}$, $\times 100)$. d Multinucleated Touton giant cell with a characteristic storiform pattern is surrounded by foamy histiocytes $(\mathrm{H} \& \mathrm{E}, \times 500)$.

ic cutaneous nodules. At the same time, similar cutaneous nodules were confirmed at both eyelids (Fig. 1a). This patient had already been diagnosed as cutaneous JXG by skin biopsy at the department of dermatology when he was 10 years old. Café au lait spots were not present. The patient's mother had a normal pregnancy and labor. This patient had no previous medical or ocular history. The family medical history was unremarkable for any major disorders.

An initial examination showed that the best-corrected distance visual acuity was 24/20 in each eye. Extraocular motility, eye movement, alignment, and the pupillary response were normal. The cornea, conjunctiva, and sclera showed no abnormal findings. The anterior chamber had a normal depth and was quiet. There were no nodules on the iris in each eye. Intraocular pressure and fundus examinations were normal. The size of a yellowish-brown mass at the left inner canthus was $5 \times 10 \mathrm{~mm}$ in diameter and elastic hard with central ulceration (Fig. 1b). The lacrimal punctum was not obstructed by the mass (Fig. 1c). However, a local excision was required because the mass had a risk of malignancy in terms of appearance of ulceration, prevention from his visual field as right gaze, and avoiding dacryoma. The mass was totally surgically ex- 
cised along the left upper eyelid with sutureless technique on August 21, 2013. This operation was performed without complications. Thirty-six months after the resection, the patient had no local recurrence (Fig. 1d). Histopathological examinations were performed for the excised mass.

The specimen of the mass was fixed in $10 \%$ buffered formaldehyde solution and processed for histopathological examinations. Two-micrometer-thick sections were prepared for microscopic examination and stained with hematoxylin and eosin (H\&E). A microscopic examination of a gross section showed a partitioned structure with connective tissue and diffuse infiltration with small cells localized in the dermal layer (Fig. 2a). Acanthosis was observed. Nodules mainly consisted of abundant foamy histiocytes and lymphocytes with partial hemorrhage (Fig. 2b). Multinucleated giant cells were observed inside a diffuse granuloma (Fig. 2c). A high-magnification image of a multinucleated giant cell is shown in Figure 2d. Many nuclei were arranged in a storiform pattern. The cytoplasm of giant cells showed eosinophilia, and marginal vacuolation of the cytoplasm outside the nucleus was observed. Based on these findings, we considered that these multinucleated giant cells were Touton giant cells. Touton giant cells were scattered throughout the lesion in association with moderate numbers of lymphocytes and histiocytes with a foamy cytoplasm (Fig. 2d). There was no malignant appearance, such as nuclear atypia, an increased number of nucleoli, and anisokaryosis. The diagnosis of JXG in the eyelids was made based on the histopathological findings and clinical manifestations.

\section{Discussion}

JXG is an uncommon disorder. JXG was first described by Adamson [29], who defined single or multiple cutaneous nodules in infancy as congenital xanthoma multiplex in 1905. JXG was named according to the appearance of cells using a microscope and was widely recognized in 1954 [30]. JXG has a bimodal distribution, under 2 years and 40 years [20]. Multiple lesions are more frequent in children aged younger than 6 months [31]. Therefore, this JXG patient was rare in terms of age of onset and multiple nodules.

JXG is mainly diagnosed by only characteristic clinical findings. Avoiding performance of histopathological examinations sometimes leads to misdiagnosis of JXG. Moreover, nodules, which are frequently observed in JXG, spontaneously regress. The pathogenesis of JXG remains unclear. The findings of macrophages and giant cells suggest that JXG is an inflammation-related and/or nonspecific injury disorder [32]. A histopathological examination is necessary to make an accurate diagnosis of JXG. The histopathology of JXG is used to diagnose the characteristic histopathological features of reactive granuloma containing foamy histiocytes, foreign body giant cells, Touton giant cells with a surrounding wreath of
Table 1. Classification of non-Langerhans cell histiocytoses [33]
Cutaneous non-Langerhans cell histiocytoses

Juvenile xanthogranuloma family

Benign cephalic histiocytosis

Juvenile xanthogranuloma

Generalized eruptive histiocytoma

Adult xanthogranuloma

Progressive nodular histiocytosis

Non-juvenile xanthogranuloma cutaneous histiocytoses

Solitary reticulohistiocytoses

Non-Langerhans dendritic cell histiocytosis

Indeterminate histiocytosis

Cutaneous with a major systemic component

Juvenile xanthogranuloma family

Xanthoma disseminatum

Non-juvenile xanthogranuloma family

Multicentric reticulohistiocytosis

Systemic non-Langerhans cell histiocytoses

Juvenile xanthogranuloma family

Erdheim-Chester disease

Non-juvenile xanthogranuloma family

Sinus histiocytosis with massive lymphadenopathy

nuclei, histiocytes, lymphocytes, and eosinophils. We observed these findings in our patients.

JXG is classified as one form of non-Langerhans cell histiocytosis (non-LCH) histopathologically. Non-LCH consists of a variable group of disorders and comprises histiocytes that are not consistent with the criteria for diagnosis of Langerhans cells. Many disorders within nonLCH make diagnosis difficult. Non-LCH was mainly divided into 3 groups by Weitzman and Jaffe [33] (Table 1). According to this classification, patients with JXG who only have skin lesions without systemic disorders belong to one of the "cutaneous non-LCH" disorders.

Diagnosis of JXG is suspected in patients with obvious cutaneous yellowish-orange lesions. JXG sometimes presents as a multisystem disease. Ocular involvement is one symptom of extracutaneous JXGs. Ocular involvement of JXG was first recognized in 1949 by Blank et al. [26]. Only $0.3-10 \%$ of patients with cutaneous JXG were reported to have ocular involvement $[2,14]$. Therefore, ocular involvement of JXG is rare. Cutaneous JXG children under 2 years are at high risk for ocular involvement [5]. Cutaneous lesions of JXG can be confirmed before or after ocular diagnosis [2]. In our case, multiple nodules on both eyelids developed after or at the same time as cutaneous lesions when our patient was 10 years old. Within ocular involvements, eyelid involvements were found in $6-25 \%$ of patients $[15,32]$. Most reports of JXG were a 
solitary lesion in the eyelid [19-22, 28]. Because previous reports only showed a solitary lesion in the eyelid, the finding of multiple nodules in the eyelids in our patient is rare.

Dehner [3] reported that the mean age of 174 JXG patients with cutaneous lesions was 3.3 years (median, 1 year). Samara et al. [15] reported that periocular JXG appeared at a later age, at a mean age of 6.5 years (median, 2.1 years). The age of onset of JXG in our patient was 10 years. Within ocular involvement, the iris was the most common site of the lesions (68\%). The conjunctiva was the second (19\%) and the eyelid (6\%) was the third most common site. Eyelid and conjunctiva JXGs are also rare and have a more benign course compared with JXG of the iris, which causes spontaneous hyphema with visual loss [15].

Most reported cases of JXG were diagnosed histopathologically after surgical resection. Kuruvilla et al. [28] successfully used topical corticosteroids for treating the eyelids of a patient with JXG. In our case, a mass in the left upper eyelid was surgically resected without topical corticosteroids. Resection was performed because this mass had a risk of malignancy in terms of the appearance of ulceration and disturbance of the visual field in terms of prevention from his visual field as right gaze.

JXG is rarely linked to systemic manifestations. In particular, JXG is associated with neurofibromatosis type 1 (NF1) and juvenile chronic myelogenous leukemia (JCML) [34, 35]. JXG might be a precursor lesion of NF1. According to a report by Cambiaghi et al. [34], one of five to six patients with NF1 had JXG during the first 3 years of life. Zvulunov et al. [35] studied triple associations among JXG, NF1, and JCML by a systematic review of the literature. They showed that children with NF1 and JXG had a 20- to 32-fold higher risk for JCML than did patients with NF1 without JXG [35]. In our case, café au lait spots of NF1 or abnormalities of blood cells were not observed. However, while our patient did not have NF1 or JCML at this time, we consider that we should screen for NF1 and JCML in the future based on these previous reports.

In summary, we describe a case of JXG that appeared on both eyelids in addition to other cutaneous lesions. Recurrence of a mass that was removed at the left inner canthus has not been observed. Systemic observations will be necessary for diseases, such as NF1 and JCML, at periodic intervals.

\section{Statement of Ethics}

This article is a case report. Ethical review in Japan is not necessary with a case report. Nobody can identify personal information from this article. Moreover, we cannot reveal this patient's information, too.

\section{Disclosure Statement}

The authors declare that there are no financial or other conflicts of interest.

\section{References}

1 Hernandez-Martin A, Baselga E, Drolet BA, Esterly NB: Juvenile xanthogranuloma. J Am Acad Dermatol 1997;36:355-367.

2 Chang MW, Frieden IJ, Good W: The risk intraocular juvenile xanthogranuloma: survey of current practices and assessment of risk. J Am Acad Dermatol 1996;34:445-449.

3 Dehner LP: Juvenile xanthogranulomas in the first two decades of life: a clinicopathologic study of 174 cases with cutaneous and extracutaneous manifestations. Am J Surg Pathol 2003;27:579-593.

4 Jung T, Emmert S, Günzl HJ, Neumann C, Rünger TM: Congenital manifestations of juvenile xanthogranuloma (large nodular form). Hautarzt 2000;51:423-426.

5 Cypel TK, Zuker RM: Juvenile xanthogranuloma: case report and review of the literature. Can J Plast Surg 2008;16:175-177.
6 Chaudhry IA, Al-Jishi Z, Shamsi FA, Rilley F: Juvenile xanthogranuloma of the corneoscleral limbus: case report and review of the literature. Surv Ophthalmol 2004;49:608614.

7 Orsey A, Paessler M, Lange BJ, Nichols KE: Central nervous system juvenile xanthogranuloma with malignant transformation. Pediatr Blood Cancer 2008;50:927-930.

8 Lin L, Salisbury EL, Gardiner I, Varikatt W: Solitary juvenile xanthogranuloma in the lung of a young adult. Pathology 2011;43: 503-507.

9 Yeh BM, Nobrega KT, Reddy GP, Qayyum A: Juvenile xanthogranuloma of the heart and liver: MRI, sonographic, and CT appearance. AJR Am J Roentgenol 2007;189:202-204.
10 Suson K, Mathews R, Goldstein JD, Dehner LP: Juvenile xanthogranuloma presenting as a testicular mass in infancy: a clinical and pathologic study of three cases. Pediatr Dev Pathol 2010;13:39-45.

11 Yamada K, Yasui M, Sawada A, Inoue M, Nakayama M, Kawa K: Severe persistent bone marrow failure following therapy with 2-chlorodeoxyadenosine for relapsing juvenile xanthogranuloma of the brain. Pediatr Blood Cancer 2012;58:300-302.

12 Jans SR, Schomerus E, Bygum A: Neurofibromatosis type 1 diagnosed in a child based on multiple juvenile xanthogranulomas and juvenile myelomonocytic leukemia. Pediatr Dermatol 2015;32:29-32.

13 Freyer DR, Kennedy R, Bostrom BC, Kohut G, Dehner LP: Juvenile xanthogranuloma: forms of systemic disease and their clinical implications. J Pediatr 1996;129:227-237. 
14 Karcioglu ZA, Mullaney PB: Diagnosis and management of iris juvenile xanthogranuloma. J Pediatr Ophthalmol Strabismus 1997; 34:44-51.

15 Samara WA, Khoo CT, Say EA, Saktanasate J, Eagle RC Jr, Shields JA, Shields CL: Juvenile xanthogranuloma involving the eye and ocular adnexa: tumor control, visual outcomes, and globe salvage in 30 patients. Ophthalmology 2015;122:2130-2138.

16 DeBarge LR, Chan CC, Greenberg SC, McLean IW, Yannuzzi LA, Nussenblatt RB: Chorioretinal, iris, and ciliary body infiltration by juvenile xanthogranuloma masquerading as uveitis. Surv Ophthalmol 1994;39: 65-71.

17 Wertz FD, Zimmerman LE, McKeown CA, Croxatto JO, Whitmore PV, LaPiana FG: Juvenile xanthogranuloma of the optic nerve, disc, retina, and choroid. Ophthalmology 1982;89:1331-1335.

18 Hildebrand GD, Timms C, Thompson DA, Atherton DJ, Malone M, Levitt G, Laidlaw DA, Russell-Eggitt I, Taylor DS: Juvenile xanthogranuloma with presumed involvement of the optic disc and retina. Arch Ophthalmol 2004;122:1551-1555.

19 DeStafeno JJ, Carlson JA, Meyer DR: Solitary spindle-cell xanthogranuloma of the eyelid. Ophthalmology 2002;109:258-261.
20 Hayashi N, Komatsu T, Komatsu T, Hiroi M, Ueno H: Juvenile xanthogranuloma presenting with unilateral prominent nodule of the eyelid: report of a case and clinicopathological findings. Jpn J Ophthalmol 2004;48:435-439.

21 Nishina S, Azuma N, Miyauchi J, Kaneko T: Surgical treatment of recurrent juvenile xanthogranuloma of the eyelid. Jpn J Ophthalmol 2004;48:598-599.

22 Chalfin S, Lloyd WC 3rd: Juvenile xanthogranuloma of the eyelid in an adult. Arch Ophthalmol 1998;116:1546-1547.

23 Johnson TE, Alabiad C, Wei L, Davis JA: Extensive juvenile xanthogranuloma involving the orbit, sinuses, brain, and subtemporal fossa in a newborn. Ophthal Plast Reconstr Surg 2010;26:133-134.

2424 Olmo N, Barrio-Barrio J, Moreno-Montañés J, Panizo A: Conjunctival juvenile xanthogranuloma in a preschool child. Ocul Immunol Inflamm 2013;21:403-404

25 Zimmerman LE: Ocular lesions of juvenile xanthogranuloma. Nevoxanthoedothelioma. Am J Ophthalmol 1965;60:1011-1035.

26 Blank H, Eglick PG, Beerman H: Nevoxantho-endothelioma with ocular involvement. Pediatrics 1949;4:349-354.

27 Zimmerman LE: Juvenile xanthogranuloma. Trans Am Acad Ophthalmol Otolaryngol 1965;69:412-442.
28 Kuruvilla R, Escaravage GK Jr, Finn AJ, Dutton JJ: Infiltrative subcutaneous juvenile xanthogranuloma of the eyelid in a neonate. Ophthal Plast Reconstr Surg 2009;25:330-332.

29 Adamson HG: A case of congenital xanthoma multiplex. Society intelligence. The Dermatological Society of London. Br J Dermatol 1905; 17:222.

30 Helwig EB, Hackney VC: Juvenile xanthogranuloma (nevoxantho-endothelioma). Am J Pathol 1954;30:625-626.

31 Cornelia H, Mona EB, Gordon S, Abel RM: Juvenile xanthogranuloma: a case report of a preterm baby. J Pediatr Surg 2006;41:573575.

32 Pajaziti L, Hapçiu SR, Pajaziti A: Juvenile xanthogranuloma: a case report and review of the literature. BMC Res Notes 2014;7:174.

33 Weitzman S, Jaffe R: Uncommon histiocytic disorders: the non-Langerhans cell histiocytoses. Pediatr Blood Cancer 2005;45:256-264.

34 Cambiaghi S, Restano L, Caputo R: Juvenile xanthogranuloma associated with neurofibromatosis 1: 14 patients without evidence of hematologic malignancies. Pediatr Dermatol 2004;21:97-101.

35 Zvulunov A, Barak Y, Metzker A: Juvenile xanthogranuloma, neurofibromatosis, and juvenile chronic myelogenous leukemia. World statistical analysis. Arch Dermatol 1995;131:904-908. 